\title{
EVOLUCIÓN DE LA SUPLEMENTACIÓN, EL CONSUMO DE PASTURA Y LA PRODUCCIÓN DE LECHE EN SISTEMAS LECHEROS DE ARGENTINA
}

\author{
LaZZARINI*, B. ${ }^{1}$; BaUdRACCO, J. ${ }^{1}$; DemarChI, E. ${ }^{2}$; \\ LOVINO, D. ${ }^{2} \&$ JÁUREGUI, J.M. ${ }^{1}$
}

\begin{abstract}
RESUMEN
La producción individual de leche, el consumo de pasturas y suplementos están asociados a la rentabilidad de los tambos. Se analizó información de 40 tambos de la región central de Santa Fe, durante el período 2004-2012, para investigar la evolución de la producción lechera y el consumo de pasturas y suplementos. Los resultados muestran que la cantidad de suplementos consumidos por vaca en ordeño (VO) se incrementó marcadamente (65\%) en los ocho años analizados, lo que permitió un incremento moderado de la carga animal (35\%) y un leve incremento de la producción individual de leche $(9,5 \%)$. Sin embargo, el consumo de pasturas por vaca y por hectárea disminuyó en el mismo período. Algunas causas que explicarían la baja respuesta en leche por vaca frente a una alta adición de suplementos podrían ser las siguientes: alta tasa de sustitución, baja calidad de los suplementos, y falta de infraestructura en los tambos.

Palabras claves: suplementos, producción de leche, sistemas lecheros, tasa de sustitución.
\end{abstract}

\section{SUMMARY}

\section{Evolution of supplements and pasture feeding and milk production on dairy farms of Argentina.}

Individual milk yield and pasture and supplement consumption are factors related to dairy farm's profitability. To investigate the evolution of milk production and supplement and pasture consumption, data of 40 dairy farms of the central region of Santa Fe were analyzed from 20042012. Results showed a $65 \%$ increase in the amount of consumed supplements per cow, allowing a moderate increase in the stocking rate $(35 \%)$, and an increase in individual milk production $(9,5 \%)$.

1.- Facultad de Ciencias Agrarias, Universidad Nacional del Litoral. Kreder 2805. (3080) Esperanza, provincia de Santa Fe. Email: belen_lazzarini@yahoo.com.ar

2.- CREA Santa Fe Centro, Argentina.

Manuscrito recibido el 30 de junio de 2014 y aceptado para su publicación el 10 de octubre de 2014. 
However, pasture consumption per cow and per hectare showed a decrease for the same period. Some causes that would explain the low response in milk production per cow with high addition of supplements could be: high substitution rate, low quality of supplements, and lack of adequate infrastructure on dairy farms.

Key words: supplements, milk production, dairy systems, substitution rate.

\section{INTRODUCCION}

El precio de la leche en Argentina es uno de los más bajos en el mundo (Hemme 2009); consecuentemente, para lograr que la producción de leche sea rentable, deben utilizarse alimentos de bajo costo. La Alfalfa es un recurso alimenticio de bajo costo cuando se utiliza adecuadamente en la región central de Santa Fe. Sin embargo, en los últimos años los sistemas lecheros argentinos han experimentado un incremento en la cantidad de suplementos suministrados por vaca y una reducción en la proporción de pastura aprovechada en pastoreo directo (FunPEL, 2013).

El incremento en el nivel de suplementación ha tenido como objetivo principal aumentar la producción individual de leche (litros/vaca/día), a fin de mejorar la rentabilidad de los establecimientos. Sin embargo, el incremento de la rentabilidad a partir de la suplementación no siempre se logra, debido a que la respuesta a la suplementación puede ser muy variable, dependiendo de varios factores relacionados a las vacas, los alimentos y el manejo de ambos.

La respuesta en leche a la suplementación puede ser definida como el aumento en producción de leche por $\mathrm{kg}$ de materia seca (MS) de suplemento consumido. Si toda la energía proveniente del suplemento consumido es transformada en leche, un $\mathrm{kg}$ de suplemento consumido (2,9 Mcal/
kgMS) permitiría una respuesta teórica en leche de 2,3 lt (con un contenido de 7,7 \% de sólidos; grasa + proteína). Esta sería la respuesta máxima a obtener con el alimento extra consumido, asumiendo que toda la energía es convertida en leche (Holmes y Roche, 2007). Sin embargo, en la práctica, la respuesta en producción es menor que la máxima posible esperada. Esto se debe a que el consumo de suplemento causa, por un lado, una disminución en el consumo de pasturas (es decir que el consumo total de MS no aumenta), y por otro que los nutrientes provenientes del alimento extra se utilicen para incrementar el peso vivo de la vaca (Holmes \& Mathews, 2001) o para mantenimiento extra en condiciones de estrés.

El objetivo del presente trabajo fue investigar la relación entre el consumo de suplementos (concentrados + silaje + heno) y de pastura con la producción de leche y su evolución a través de ocho años en tambos comerciales de la provincia de Santa Fe, Argentina.

\section{MATERIALES Y METODOS}

Se analizaron ocho años (2004-2012) de información física de 40 tambos, pertenecientes a la región centro-oeste de Santa Fe, Argentina. La base de datos analizada contiene un total de 127 tambos

74 | Revista FAVE - Ciencias Agrarias 13 (1 - 2) 2014 